\title{
LA CONDICIÓN DE LA APORÍA Y LA APUESTA KANTIANA
}

\section{Manuel Altamirano*}

Resumen: En este trabajo reviso tanto la constitución contemporánea (postestructuralista) de lo puede llamarse la condición aporética de nuestro pensamiento filosófico, basándome principalmente en textos de Jaques Derrida y Ernesto Laclau, como en la constitución de esta condición aporética por parte de Immanuel Kant en la Dialéctica Trascendental de la Crítica de la Rarón Pura. Centrándome en este tema, (1) analizo la apuesta por la cual Kant se abre paso ante la imposibilidad de tránsito implicada por esta aporía o antinomia para desembocar en una filosofía práctica que privilegia la idea de libertad, y (2) reviso la relación de esta condición aporética con la fundamental idea trascendental de lo incondicionado, y otros conceptos vinculados. Luego, en un apartado final, establezco cinco grandes diferencias que impone nuestra época con respecto a la solución kantiana, argumentado por qué y en qué lugar del sistema kantiano debemos provocar una cesura, rescatando sólo la actitud por la cual se abre paso ante la condición aporética, y que podemos emular todavía hoy, pero dejando de lado ideas como imperativo categórico o deber, conceptos ante los cuales propongo desplazamientos más acordes a nuestras constricciones actuales.

Palabras clave: aporía, incondicional, postestructuralismo, kantismo, apuesta ontológica.

Abstract: In this paper I look over the contemporary (poststructuralist) constitution of what can be called the aporetic condition of our philosophical thought, mainly based on Jaques Derrida's and Ernesto Laclau's works, as well as the constitution of this special condition in Immanuel Kant's Trascendental Dialectic (Critique of Pure Reason). Focusing on this subject, (1) I analize the wager whereby Kant opens a way to break through the imposibilty of any resolution implied by this antinomy, a bet that leads to his practical philosophy, and (2) I check out the relation between this apory and the foundational concept of the

* Licenciado en Filosofía por la Universidad Nacional de Córdoba. Becario del CONICET. Se encuentra en curso su tesis de doctorado sobre "El rol de las oposiciones filosóficas en la crisis postestructuralista. Para una reconsideración del concepto de diferencia en el contractualismo contemporáneo". Dirección electrónica: sofos69@hotmail.com. 
unconditional (Unbedingt). In a final section, I establish five main diferences that our age demands regarding this kantian proposal, explaining why and on which particular moment of the kantian philosophy we should interrupt the unity of the system, preserving the attitude and the performative decision whereby he opens a way through the antinomy, but rejecting such concepts as duty or categorical imperative, concepts that should be replaced by new ones, more in agreement with our present constrictions.

Key words: antinomy, unconditional, poststructuralism, kantianism, ontological bet.

1. Hoy por hoy, en nuestro escenario contemporáneo, nos toca enfrentarnos a un particular tipo de problema que no tiene solución posible y que adopta entonces la forma de una condición incómoda e irrenunciable de nuestro pensamiento. Es el tema de la aporía y sus formas. Y más exactamente, el de las actitudes prácticas que podemos adoptar -si algo así como una solución resulta ya imposible- frente a las consecuencias de la condición aporética, que pone en entredicho el sentido, la identidad y los fundamentos que tuvo alguna vez la filosofía.

El tema de la aporía puede abordarse desde diversos ángulos, aunque la totalidad de sus alcances es intrínsecamente incalculable. Está crecientemente arraigado en algunas redes conceptuales y problemáticas contemporáneas -me refiero especialmente al transcurso conceptual producido entre el auge del estructuralismo y su problematización radical, que produce ciertas consecuencias; entre ellas, el giro postestructuralista o posfundacionalista y todo lo que eso implica, incluida la teoría de la hegemonía-. Es preciso, entonces, limitarse a examinar alguna o algunas de sus posibles formulaciones, cada una de las cuales ilumina diferentes caras de un cuerpo informe y aún desconocido.

Algunas formulaciones de Derrida son, sin embargo, inevitables para casi cualquier comienzo, ya que el problema aparece a lo largo de sus textos. Fuerza de Ley: el fundamento místico de la autoridad es un ejemplo. Allí la aporía es presentada en la forma de un cuestionamiento a la oposición entre el derecho y la justicia, y la oposición entre lo necesario y lo imposible que subyace en la exposición final de las tres formas de la 
aporía, sobre "la epokbé de la regla", la "obsesión de lo indecidible" y "la urgencia que obstruye el horizonte del saber"1.

Sin embargo, no podemos homologar esta condición, que llamamos de la aporia, a lo que podría pensarse como uno de sus modos (derecho/justicia o necesidad/imposibilidad, por ejemplo); de hecho, estrictamente, el concepto de modo sería impropio aquí, porque requiere de una sustancia que adopte las diferentes modalidades, y no es posible ya pensar en términos de sustancia. Tampoco es posible postular una separación entre la forma y el contenido, como si existiera una forma del problema que estuviera más allá de los "contenidos" particulares de esa "forma", es decir, las oposiciones particulares de conceptos que debemos elegir cada vez. De cualquier manera, algo permanece como por debajo de estas variaciones temáticas y conceptuales particulares, y es el problema de la aporía en toda su magnitud.

Podría presentarse entonces a la aporía como la subsistencia paradójica de una relación imposible pero a la vez necesaria entre las funciones diferenciales ${ }^{2}$ implicadas por algunas oposiciones de conceptos. En sus libros de los años sesenta, como De la Gramatología, La escritura y la diferencia, o Márgenes de la filosofía, Derrida parece sugerir esto, estudiando muchas de esas oposiciones, aunque sin llevar a cabo un tratamiento sistemático de ellas, sino más bien implícito, aún cuando señala, en la primera mitad de De la Gramatologia, que estas oposiciones resultan más o menos análogas, quizás "funcionalmente" (aunque no lo dice asî), a la oposición entre el habla y la escritura (esto es, por una parte, la función de inmediatez, naturalidad y verdad del habla, y por otra parte la función suplementaria, artificial e instrumental de la escritura). La cadena suplementaria es un mero instrumento utilizado para reafirmar, por vía

${ }^{1}$ Cf. Derrida, Jaques, Fuerza de Ley, el fundamento mistico de la autoridad, Madrid, Tecnos, 1997, pp. 52-67.

${ }^{2}$ Función en el sentido de su pertenencia a un sistema de diferencias -el sistema de conceptos del logocentrismo, y su lógica oposicional-, que determina para esos conceptos una función estructural determinada. La aporía supondrá la sistematización conceptual de una función estructural que tiene como consecuencia inesperada la imposibilidad de la sistematización y de la estructura. 
negativa, la identidad de la función privilegiada, cuya prevalencia está previamente establecida, transformando a la oposición -y con ello a la lógica oposicional que rige la metafísica de la presencia y del logos- en un diseño más o menos ficticio y teleológico (arbitrario, parcial pero hegemónico, casi totalitario) ${ }^{3}$.

La condición de la aporía no existió siempre, ya que es un resultado reciente de la orientación seguida por algunos sectores de la filosofía contemporánea. Este problema, tal como podemos visualizarlo hoy, no empieza a aparecer sino con la "Dialéctica trascendental" de Kant, un antecedente fundamental en el que nos detendremos pacientemente.

Antes de eso, podría ser gráfico tener a la vista una lista de algunas de estas oposiciones centrales a partir de las cuales se percibe la condición de la que hablamos, recogidas a lo largo de los textos tempranos de Derrida, y alimentada con oposiciones similares presentes en otros autores. Es preciso tomar el recaudo de alinear correctamente las funciones que cumplen, y que hemos afirmado que son análogas entre sít

${ }^{3}$ La importancia de las oposiciones está en directa relación con algo así como la deconstrucción: “...Derrida plantea la deconstrucción como «solicitación»: este «hacer temblan» el edificio de la metafísica es algo que acontece desde las «fisuras» del mismo, fisuras que indican que no está tan «bien construido». El medium de la deconstrucción lo constituyen los «indecidibles», esas unidades de simulacro que se hallan "entre» las oposiciones binarias, y que indican que la lengua "ya» se está deconstruyendo. Como falsas unidades verbales, ponen en una situación de parálisis al binarismo de la metafísica occidental, ya que generan un estado de no certeza (en la idea de una lógica del «ni/ni») que "hace temblan» a una metafísica pensada según el esquema arkhico, donde hay una voz del padre, del logos o de Dios, que determina lugares y jerarquías" (Cragnolini, Mónica, "Para una 'melancología' de la alteridad: diseminaciones derridianas en el pensamiento nietzscheano", en http://www.jacquesderrida.com.ar).

4 "Se trata ante todo de poner en evidencia la solidaridad sistémica e bistórica de conceptos y de gestos de pensamiento que muchas veces se cree poder separar inocentemente. El signo y la divinidad tienen el mismo lugar y el mismo momento de nacimiento..." (p. 20, subrayado nuestro), o bien: "Todas las posibilidades de la serie suplementaria, que tienen entre sí relaciones de sustitución metonimica, nombran indirectamente al peligro mismo, al horizonte y a la fuente de todo peligro 
Ubicaremos siempre, arbitrariamente, la función privilegiada a la izquierda y la función suplementaria a la derecha ${ }^{5}$.

Habla/escritura; Alma/Cuerpo; Lo Mismo/Lo Otro;

Necesidad/Contingencia; Necesario/Imposible;

Universalidad/Particularidad; Orden/Conflicto; Sistema/Exterior

constitutivo; Identidad /Diferencia (como diffërance);

Homogeneidad/Heterogeneidad; Cierre (estructura)/Apertura (génesis);

Contradicción/Antagonismo; Esencia /Accidente; Unidad,

Identidad/Aporía; Oposición/Aporía; Logos, habla /Escritura, grafía;

Significado/Significante; Vida/Muerte; Presencia/Ausencia;

Adentro/Afuera; Inmediatez/Re-presentación; Natural (naturaleza)

/Artificial (cultura); Conciencia/Inconsciente; Forma /Contenido;

Realidad/Apariencia; Derecho/Justicia (Derrida); Dialéctica/Tragedia;

Presencia/Ausencia, diferimiento; Totalitarismo/Política; Administración, policía/Política; Filosofía política/Política; Poder constituido/Poder constituyente

El tratamiento de estas oposiciones está condicionado, como dijimos, por el privilegio hacia la voz, o el habla viva y presente, frente a la

determinado, al abismo a partir del cual se anuncian todas las amenazas" (Derrida, Jacques, De la Gramatología, Buenos Aires, Siglo XXI, 1971, p. 232, subrayado nuestro).

${ }^{5}$ No está de más aclarar que esta lista no pretende ser exhaustiva, ni se ofrece como parte de un método particular de lectura, que nunca fue un objetivo en el pensamiento de la deconstrucción ni lo es en nuestro acercamiento. Sólo queremos precisar algunos de los conceptos a los que nos referimos y llamar la atención sobre el amplio margen de discursos en los que han sido y son protagonistas principales (ya sea como oposición, o alguno de sus términos aislados, que siempre mantienen la relación implícita con su opuesto). Para una precaución radical sobre la confianza ingenua en estos eventuales sistemas cuasitaxonómicos de metáforas y tropos (como el proyecto radical de "ciencia" de lo ideológico basado en la homología de ciertos equivalentes generales, propuesto por J. J. Goux en Los equivalentes generales en el maraismo y el psicoanálisis, Buenos Aires, Caldén, 1973) véase Derrida, J., "La mitología blanca. La metáfora en el texto filosófico", en Márgenes de la Filosofía, Madrid, Cátedra, 1994, pp. 268-269. 
escritura, más alejada de la plenitud del logos. Porque la phoné habría sido, para esta tradición que Derrida llama logocéntrica, la única forma capaz de transmitir, de manera inmediata y sin pérdidas, el sentido del logos. El sistema del oírse-hablar, siempre preferible, implicaba la inmediatez, la veracidad del significado -la verdad, su no-exterioridad y no-contingencia, o sea, su interioridad originaria y su necesidad-, resolviendo así de antemano problemas siempre amenazantes. "Este movimiento habría tendido en apariencia, como hacia su telos, a confinar la escritura en una función secundaria e instrumental: traductora de un habla plena $y$ plenamente presente (...) intérprete de un habla originaria"'. Nos extendemos en estas ya conocidas palabras sólo para acentuar el lugar secundario e instrumental de esa función relegada, y la preferencia del habla, la presencia, la conciencia, a la que tendió el pensamiento metafísico onto-teo-teleo-lógico como hacia una finalidad natural, necesaria y primigenia ${ }^{7}$.

El desarrollo posterior de muchos de los textos de Derrida, desde el tratamiento del caso de Saussure y el estructuralismo, en la Gramatología, hasta Fuerza de Ley, o Canallas: dos ensayos sobre la razón, se basa en una variación del mismo tema, el pensamiento de este problema inmenso que supone enfrentar a la cadena oposicional $-\mathrm{y}$ su tradicional lógica de relevamiento- con la condición aporética, que podríamos considerar asentada en el cuestionamiento del rol de la función oposicional privilegiada. Respecto del problema irresuelto de Saussure, sólo diremos que la oposición habla/escritura, dominante aquí como significado/significante, es suscrita por Saussure y en cambio enfrentada por Derrida con el pensamiento de la aporía, o el problema de la subversión gramatológica del logocentrismo (y de nuevo, esto no es una

\footnotetext{
${ }^{6}$ Gramatologia, p. 13.

7 "Si pensamos el logocentrismo desde la lógica binaria que se hace patente en el pensamiento platónico (sensible/inteligible, opinión/conocimiento, engaño/verdad), la escritura se halla del lado oscuro y engañoso de la tabla, en la medida en que representa una materialización de la voz" (Cragnolini, M., "Deconstrucción y pensar en las fisuras", en http://www.jacquesderrida.com.ar).
} 
inversión de los términos ni una síntesis plena como auflbebung ${ }^{8}$ ), al mostrar que la escritura como notación gráfica es sólo una especie más de la Escritura en general -la escribe a veces con mayúscula-, esto es, la memoria, las huellas, la notación en su amplio sentido ${ }^{9}$, tal como lo es, además de la escritura alfabética o fonética, la escritura ideográfica, los sistemas de jeroglíficos, los caracteres chinos, algunas partes de la matemática y el habla ${ }^{10}$.

Ahora bien, venimos diciendo que esta diferencia entre escritura y Escritura fue relegada al olvido, desde que el habla, esa especie particular

8 "Las formas de enfrentarse a la historia de la metafísica son diversas: «superación», «más allá», «inversión», «subversión» son algunos de los nombres para esos modos diferentes. El deconstruccionismo se presenta, combinando algunas de estas formas, como un habitar las estructuras de la metafísica para mostrar las fisuras de las mismas. Una convicción guía a este pensamiento: no se puede, por simple decreto, ir más allá de la metafísica, tampoco se puede plantear la simple inversión de los términos o la simple destrucción del binarismo que caracteriza a la metafísica" (Ibidem).

"Para recordar todos los alcances del concepto amplio de Escritura, véase el séptimo ensayo de La escritura y la diferencia, "Freud y la escena de la escritura", especialmente la hermosa metáfora freudiana sobre el desarrollo de la memoria a nivel neuronal, dependiente del abrirse-paso (Banhung) de los estímulos de la experiencia. Las neuronas encargadas de acoger la memoria opondrían, según Freud, "rejas de contacto" al paso de estos estímulos. Dichas barreras se "doblarían" según las diversas formas que las respectivas excitaciones imprimiesen, dependiendo de su intensidad, velocidad y envergadura, retratando así sus buellas. "El abrirse-paso, el camino trazado abre una vía conductora. Lo cual supone una cierta violencia y una cierta resistencia ante la fractura" (Derrida, J., La escritura y la diferencia, Barcelona, Anthropos, 1989, p. 277), que va configurando la memoria, y que sería ya, según Derrida, una forma de la Escritura.

10 "Si «escritura» significa inscripción y ante todo institución durable de un signo (...) la escritura en general cubre todo el campo de los signos lingüísticos. En este campo puede aparecer luego una cierta especie de significantes instituidos, «gráficos» en el sentido limitado y derivado de la palabra, regulados por una cierta relación con otros significantes instituidos, por lo tanto «escritos», aun cuando sean fónicos" (De la Gramatologia, p. 58). 
de escritura, se encumbró en un lugar de universalidad vacía, que esperaba contenido particular, en un proceso que percibimos como perfectamente reproductible por la lógica hegemónica (todo el desarrollo de esta lógica de la hegemonía, como es bien sabido, es compatible y paralelo con la crítica al logocentrismo y la metafísica de la presencia propia de la Gramatología). Una vez reconocido el carácter hegemónico de la prioridad del habla, y por ello su contingencia última, la oposición "habla/escritura", y todas las otras que se relacionan por medio de una analogía funcional pasible de sustitución metonímica (y con ello la lógica oposicional logocéntrica de la cual la resolución de la oposición entre el habla y la escritura es sólo un caso), sufre una particular crisis. Esta oposición debe su existencia y el sentido mismo de su conformación binaria a la protección de la función filosófica (ontológica, epistemológica, moral) representada por los diversos términos que hemos ordenado a la izquierda de nuestra tabla. La oposición obedece al telos de lo que podríamos llamar la "conminación a la elección" de ese término. Pero ahora ese reverso negativo de lo natural y de lo universal vuelve, modificando su antiguo status, para re-apropiarse de la unidad de la oposición. Esto ocurre de la misma manera en que la Escritura, en sentido general, incluye al habla, dimensión que aparece posteriormente como responsable del sentido restringido de la escritura y de su confinación al nivel de una exterioridad prescindible. Si entonces ubicamos a esta Escritura en el polo enfrentado a la inmediatez y a la transparencia absoluta del habla, que niega la necesidad de lo universal y la universalidad de lo necesario, en el extremo que subvierte ideas como la de esencia o naturaleza, tendremos que la Escritura es parte y todo, partícula y universo de la oposición, o mejor, la perpetuidad de la oposición, la imposibilidad de su resolución en la identidad. Esta misma condición de parte y a la vez todo, o de dicotonía (como perpetuidad de la apertura a lo otro, a la alteridad), podría ser invocada de cada término de la derecha de la tabla de oposiciones (o al menos esto podría ser discutido con un margen previo de plausibilidad bastante razonable), a diferencia de lo que sucede con la oposición, reductible y equivalente a los términos $-\mathrm{O}$ la función- de la izquierda, que sí logra identificarse, o sí logra la identidad -es la identidad-. 
Esta paradójica condición de parte y todo corresponde a uno de los pensamientos posibles de lo que hemos llamado más arriba la condición de la aporía, cuyo carácter es irreductible, escapando irremediablemente a la posibilidad de elección a la que nos quiere conminar la oposición. En Emancipación y diferencia, Laclau plantea también este núcleo aporético, al que a veces llama dicotómico, a partir de un análisis del concepto de emancipación, del que se pueden establecer seis dimensiones presumiblemente necesarias, que sin embargo entran en mutua contradicción (generalmente las dimensiones que implican un "radicalismo dicotómico" con la dimensión de fundamento último de lo social al que un concepto tradicional de emancipación hace referencia) ${ }^{11}$. Un conflicto, una división, nos obliga a lidiar indefinidamente con la incomodidad de un lugar inestable, que no termina nunca de nombrarse. ¿No es acaso el conflicto -como término de la derecha en la oposición que lo enfrenta al orden- una división, una dislocación de las identidades, la marca de lo inestable que mantiene en inquietante suspenso al origen y al fin? ¿No es acaso el conflicto la disputa por la facultad de poner los nombres, y de establecer las condiciones -la verdad-? También la particularidad indica un quiebre problemático para la identidad hegemónica, que se pretende a sí misma universal. ¿Cómo justificar la prevalencia de una identidad parcial, que carece de privilegios especiales o de derecho, en su relación con el poder? La lógica de la hegemonía lo ha explicado extensamente. Así, de la mano de la imposibilidad de derecho que acosa a la elección sobre una oposición conceptual, cualquier elección de becho resultará violenta y "accidental". Sin embargo, necesaria. Imposibilidad $y$ necesidad que derivan en una indecibilidad constitutiva, ajena al espíritu de la oposición tradicional y de la función que su lógica privilegiaba; indecibilidad propia, en cambio, de la inestabilidad y el carácter obstinadamente dicotómico o antagónico de la aporía ${ }^{12}$.

${ }^{11}$ Cf. Laclau, E., Enzancipación y diferencia, Buenos Aires, Ariel, 1996, pp. 14-17. 12 "...lo que tenemos, en última instancia, es una totalidad fallida, el sitio de una plenitud inalcanzable. La totalidad constituye un objeto que es a la vez imposible y necesario. Imposible porque la tensión entre equivalencia y diferencia es, en última instancia, insuperable; necesario porque sin algún tipo de cierre, por más 
Para Derrida, entonces, y en una de sus consecuencias políticas presentadas en el marco de la discusión sobre Rousseau, esta aporía nos obliga a "neutralizar todas las oposiciones que surcan la filosofía clásica de la historia, de la cultura y de la sociedad. Antes de esta neutralización, o de esta reducción, la filosofía política procede dentro de la ingenuidad de evidencias adquiridas y sobrevenidas" 13 .

Por supuesto que sería necesario continuar la revisión, con mucha más paciencia y detalle, del enorme tejido de conceptos fundamentales en la filosofía de Derrida y de Laclau, entre otros, que no hemos podido siquiera mencionar, y que van configurando diferencialmente el problema de la aporía (como las ideas de différance, o khôra ${ }^{14}$, que son en alguna medida otros nombres de la aporía). Pero esto es imposible aquí, y nos vemos obligados a hacer un viraje algo drástico para volver a orientarnos en la dirección que en este trabajo pretendemos seguir.

2. Dijimos más arriba que el problema de la aporía es presentado, con notable precisión y una lucidez casi contemporánea, por Kant en la Crítica de la Razón Pura, específicamente en la "Dialéctica trascendental". Ésta

precario que fuera, no habría ninguna significación ni identidad" (Ibidem, pp. 9495).

13 Gramatología, p. 238.

${ }^{14}$ Por ejemplo, "...lo que Platón designa bajo el nombre de kbôra parece desafiar, en el Timeo, esa «lógica de no-contradicción de los filósofos» de la que habla Vernant, esa «lógica de la binaridad, del sí o no». Pondría de manifiesto pues, quizás, esa «lógica distinta de la lógica del logos. La khôra no es ni «sensible», ni «inteligible», pertenece a un «tercer género» (triton genos, 48e, 52a). Tampoco podemos decir de ella que no es ni esto ni aquello, o que es a la vez esto y aquello...", o "AAccederemos al pensamiento de la khôra si nos fiamos aún de la alternativa logos / mythos? ¿Y si este pensamiento designara incluso un tercer género de discurso? ¿Y si, quizás como en el caso de la kbôra, esta apelación al tercer género no fuera más que el tiempo de un desvío para indicar un género más allá del género? ¿Más allá de las categorías -de las oposiciones categoriales sobre todoque, ante todo, permiten aproximarlo o decirlo?" (Derrida, J., Khôra, trad. Diego Tatián, Alción, Córdoba, 1995). 
constituye la segunda división de la "Lógica trascendental", siendo la primera división la "Analítica trascendental", en la que Kant se encarga de establecer el legítimo uso lógico del entendimiento, derivando sus conceptos puros, o categorías, y ciertos principios del entendimiento que rigen el uso de estas categorías. La noción de un concepto puro del entendimiento se deriva de la división analítica que hace Kant entre el entendimiento y las formas de la intuición (estudiadas en la "Estética trascendental", y que son el espacio y el tiempo como formas de la sensibilidad). Esta división corresponde también a los dos elementos principales de nuestro conocimiento, la intuición (receptividad de las impresiones) y los conceptos (espontaneidad por la que se piensan estas representaciones de la intuición). Estas dos fuentes del conocimiento son consideradas por Kant como condiciones de posibilidad de la experiencia, perspectiva que supuso, como es bien sabido, una revolución dentro de la filosofía, de enormes consecuencias para la metafísica o la epistemología, entre otras áreas.

El examen de estas facultades revela ciertos conocimientos a priori, es decir, determinables de manera independiente de la experiencia. Los conocimientos dependientes de la experiencia son empíricos, es decir, a posteriori, y no comportan la necesidad ni la universalidad de los conocimientos a priori (algunos ejemplos de conocimiento a priori son las proposiciones de la matemática, o la proposición "todo cambio exige una causa"). El entendimiento, y también, en otro nivel más alto, la razón, son facultades que dan reglas y principios (respectivamente) de unidad y ordenamiento a las intuiciones de la sensibilidad. De hecho, el objetivo principal de ambas facultades es la permanente síntesis de ese conjunto de impresiones representadas por formas de la intuición y por conceptos del entendimiento ${ }^{15}$. Las reglas del entendimiento y los principios de la razón, según Kant, pueden ser determinados a priori.

\footnotetext{
15“Entiendo por sintesis la operación de reunir las representaciones unas con otras y comprender toda su diversidad en un solo conocimiento. Esta síntesis es pura, cuando la diversidad no es empírica, sino dada a priori" (Kant, I., Crítica de la Razón pura, Buenos Aires, Losada, 1938, Analítica, III, 10, p. 221).
} 
Ahora bien, uno de los descubrimientos más importantes de Kant es la idea de juicio sintético a priori, es decir, un juicio que hace extensivo nuestro conocimiento a priori (o sea, que no se limita meramente al despliegue analítico de cuestiones implicadas ya por la definición misma de un concepto, sino que relaciona ese concepto con algo que no está contenido en su propia definición, pero siempre en el terreno a priori del entendimiento y de la razón, y nunca en el terreno de la experiencia, que es a posteriori). Estos juicios sintéticos, cuya posibilidad parecía estar ligada sólo al dominio de la experiencia (o sea, juicios sintéticos a posterior), se muestra como posible y necesaria también en el uso teórico de la razón (por ejemplo, todas los juicios matemáticos son sintéticos a priori, así como los principios de la geometría, de la física, e incluso de la metafísica). El objeto de la crítica de la razón pura será, entonces, determinar cómo son posibles estos juicios sintéticos a priori, y cuál es su uso legítimo (que estará siempre referido a las reglas del entendimiento y a los principios de la razón, todos ellos a priori, a pesar de ser sintéticos, y por tanto inaplicables a la experiencia).

De ahí la idea de "trascendental", también restringida a los conocimientos a priori ${ }^{16}$, y basada en la unidad de la razón, en la comunidad de la razón de todos los seres racionales ${ }^{17}$, o en ese concepto

16 "Llamo trascendental a todo conocimiento que en general se ocupe, no de los Objetos, sino de la manera que tenemos de conocerlos, en tanto que sea posible a priori". Este conocimiento trascendental "tiene por objeto, no la naturaleza de las cosas, que es infinita, sino el entendimiento que juzga sobre la naturaleza de las cosas, y aun este entendimiento considerado solamente en relación a sus conocimientos a priori..." (CRP, Introducción, VII, p. 165).

17 "Pero debe parecer extraño, al comienzo, que la condición bajo la cual yo pienso en general y que es por lo tanto sólo una constitución de mi sujeto, haya de ser valedera al mismo tiempo para todo lo que piensa y que podamos preciarnos de fundar sobre una proposición, que parece empírica, un juicio apodíctico y universal, a saber: que todo lo que piensa está constituido como lo manifiesta en mí la expresión de la conciencia de mí mismo. La causa de esto está en que debemos necesariamente atribuir a las cosas a priori todas las propiedades que constituyen las condiciones bajo las cuales las pensamos. Ahora bien, de un 
de sujeto -sujeto que, a diferencia del cartesiano, está des-sustancializado, y pertenece también al "mundo" como conjunto de todos los fenómenos, y no como cosa en sí-, que Kant llama apercepción trascendental, y que produce la síntesis de la aprehensión, o sea, la composición o el enlace de los elementos de la diversidad de la intuición en un todo, operación que se deduce a priori, como condición de posibilidad de la experiencia. Esta apercepción trascendental supone no sólo la unidad o síntesis de la aprehensión, sino una correlativa unidad de la conciencia (de nuevo, dessustancializada, identificable con un mero "yo pienso" que debe acompañar a toda representación), que se deduce también como necesaria para la experiencia (esta necesidad deriva del fundamento trascendental de la apercepción, es decir, toda necesidad, en Kant, deriva de un fundamento a priori y relativo a los principios del entendimiento. Con esto quiero decir que la necesidad nunca procede de la experiencia).

Por supuesto que Kant, en la Crítica de la Razón Pura-que es en sí misma una radical crítica de la metafísica dogmática y sus pretensiones ilegítimas de extender el uso de los juicios sintéticos a priori en una aplicación directa e incontrolada a la experiencia (véanse las críticas a Platón y especialmente a Leibniz)-, peca de una actitud por demás sistemática y arquitectónica, que puede ser leída también como logocéntrica y teleológica (desde que piensa a la razón desde una finalidad sintética y unificadora del conjunto de los fenómenos, por ejemplo). Pero Kant está intentado restringir el uso legítimo de la razón, y su especulación trascendental y apriorística, según él mismo lo advierte innumerables veces, no está pensada para ser trasladada a una aplicación sobre conceptos de la experiencia. No es posible, entonces, descartar la lectura de Kant como si se tratase de un metafísico más. Es claro que su filosofía, incluso su filosofía crítica, conserva aún fuertes elementos de una época muy distinta a la nuestra, creyente aún en fundamentos y sistemas que nos han abandonado hace ya mucho tiempo. Sin embargo, creemos que en la lectura de Kant es todavía posible descubrir algunas claves para pensar nuestros problemas actuales. Este trabajo de reapropiación o relectura de

ser pensante no puedo tener la menor representación por medio de la experiencia externa y sí sólo por medio de la conciencia de mí mismo" (Ibidem, p. 175). 
la obra kantiana requiere un trabajo paciente y extenso, que no podemos aquí más que insinuar. Repasemos rápidamente, entonces, lo que dice acerca de los juicios sintéticos a priori y sobre esta tendencia sintetizadora de la apercepción trascendental y de la razón en general, en el capítulo que más nos interesa ahora.

3. En la introducción a la "Dialéctica Trascendental" indica Kant que tanto la verdad como los errores y la ilusión, no pertenecen a las cosas mismas, sino a la relación de esos objetos con el entendimiento, es decir, a nuestros juicios. Cuando el problema de error o contradicción afecta a juicios a priori, precisaremos una reflexión trascendental. En esta parte de la Crítica se tratará entonces de abordar las causas de ciertas ilusiones trascendentales (de nuevo, relativas exclusivamente a juicios y principios $a$ prior). Ahora bien, a diferencia de una ilusión empírica, causada por un razonamiento lógico falaz, que puede ser entonces corregido, la ilusión trascendental es tanto natural, como insoluble es decir, en términos de la aporía, necesaria, pero imposible:

La ilusión lógica que consiste en la mera imitación de la forma de la razón (la ilusión de los raciocinios falaces) se origina simplemente en una falta de atención a la regla lógica. Tan pronto, pues, como esta atención se agudiza sobre el caso presente, desaparece dicha ilusión por completo. Pero, en cambio, la ilusión transcendental no cesa, sin embargo, aun después de descubierta y de conocida claramente su vanidad, por medio de la crítica transcendental (...) La Dialéctica transcendental se contentará, pues, con descubrir la ilusión de los juicios transcendentales e impedir, al mismo tiempo, que esta ilusión engañe. Pero que (como la ilusión lógica) desaparezca y deje de ser ilusión, esto nunca lo podrá conseguir. Pues se trata de una ilusión natural, e inevitable, que descansa en principios subjetivos y los usa como objetivos (...) Hay, pues, una dialéctica natural e inevitable de la razón pura (...) una dialéctica que es irremediablemente inherente a la razón humana y que, aún después de descubierto su espejismo, no cesa, 
sin embargo, de engañar y de empujar la razón, sin descanso, a momentáneos errores, que necesitan de continuo ser remediados ${ }^{18}$.

El segundo punto de la introducción a la Dialéctica se llama "De la razón pura como asiento de la ilusión trascendental". Este nombre dice ya mucho, más aún si consideramos que "la razón es superior al entendimiento"19. La razón, entonces, obedece a esta motivación bipersintética, por la cual trata de reducir la gran multiplicidad del conocimiento del entendimiento al mínimo número de principios (es decir, ciertas condiciones generales), teniendo siempre como objetivo la unidad suprema del entendimiento.

En esa búsqueda de las condiciones generales, la razón advierte que para un condicionado dado (un fenómeno condicionado, o una regla del entendimiento, que también está condicionada, y la mayoría de los principios de la razón, aun condicionados), debe darse también la serie total de las condiciones - previas, en este caso-, y quizás una serie total de las consecuencias. A Kant, en cualquier caso no le interesa la serie de las consecuencias. En su análisis se ocupa sólo de la serie de las condiciones, que es suficiente para determinar el problema que ocupa a la Dialéctica. La razón, por tanto, dice Kant, en esta tendencia bipersintética, se remonta regresivamente en esa serie de las condiciones, y no puede detener su ímpetu sintético hasta encontrar lo incondicionado, en que esa serie de las condiciones debe sustentarse en último término ${ }^{20}$. Este es un principio

$18 \mathrm{CRP}$, tomo II, pp. 156-157.

19 “... si el entendimiento es una facultad de la unidad de los fenómenos por medio de las reglas, la razón es la facultad de la unidad de las reglas del entendimiento bajo principios. Nunca, pues, se refiere directamente a la experiencia o a algún objeto, sino al entendimiento, para dar a los múltiples conocimientos de éste unidad a priori por conceptos, la cual puede llamarse unidad de razón" (Ibidem, p. 158).

20 "...sólo lo incondicionado hace posible la totalidad de las condiciones y, recíprocamente, la totalidad de las condiciones es siempre ella misma incondicionada, así el concepto puro de razón, en general, puede ser definido por 
que Kant califica como "supremo" y que pertenece a la razón pura. La idea de lo incondicionado, identificada por Kant con la universalidad (por la universitas, o totalidad, de las condiciones) y con lo absoluto (opuesto a aquello que vale sólo parcialmente o por comparación), y en cuanto es un juicio sintético a priori de la razón pura, genera otros principios sintéticos $a$ priori, y por ello trascendentales, pero que en ningún caso pueden ser aplicados a fenómenos de la experiencia sin adquirir el estatus de trascendentes (nótese la diferencia entre "trascendental", como principio a priori y necesario, propio de la razón pura y condición de la experiencia posible, y "trascendente", que es el uso ilegítimo que se hace de un principio trascendental al aplicarlo a los fenómenos de la experiencia y no a los meros principios a priori que ordenan las reglas del entendimiento).

En el libro segundo de la Dialéctica Kant revisa el problema del transcurso entre lo trascendental y lo trascendente, problema necesario y coincidente en buena medida con el problema de la aporía tal y cual como él logra recortarlo. Nos habla allí de raciocinios dialécticos o paralogismos de la razón pura, inevitables e insolubles. Hay de ellos tres especies, equivalentes a los tres grandes temas predilectos de la metafísica dogmática. Cada uno supone una idea trascendental, cuya aplicación a los objetos de la experiencia sería trascendente y por tanto ilegítima. La primera especie de esos raciocinios sofísticos se refiere a la unidad incondicionada de las condiciones subjetivas de todas las representaciones en general (es decir, la incondicionalidad o universalidad absoluta del sujeto, o alma. Kant llama a este raciocinio dialéctico "paralogismo trascendental"). La segunda especie del argumento dialéctico tiene como contenido la unidad incondicionada de las condiciones objetivas en el fenómeno (es decir, el mundo. Este raciocinio dialéctico se llama "antinomia de la razón pura"). La tercera especie, finalmente, tendrá por tema la unidad incondicionada de las condiciones objetivas de la posibilidad de los objetos en general (es decir, Dios. Este raciocinio dialéctico se llama "ideal de la razón pura").

el concepto de lo incondicionado, por cuanto contiene un fundamento de la síntesis de lo condicionado" (Ibidem, p. 166). 
Muéstrase aquí en efecto un nuevo fenómeno de la razón humana, una antítesis natural, que nadie necesita sutilizar y llenar de trampas, ya que la razón cae en ella por sí misma y sin remedio. Cierto es que de este modo evita la razón el sopor de una convicción ficticia, producto de una ilusión unilateral; pero al mismo tiempo cae en la tentación o de abandonarse a un desesperado escepticismo o de adoptar un dogmatismo tenaz y sostener con testarudez ciertas afirmaciones, sin dar oídos ni hacer justicia a los fundamentos de la aserción opuesta. Ambas cosas son la muerte de una sana filosofía, aunque la primera en todo caso podría llamarse la eutanasia de la razón pura ${ }^{21}$.

Quisiéramos insistir en que lo incondicionado, como totalidad absoluta, es una mera idea trascendental, o sea, no tiene referencia empírica alguna, no puede probarse empíricamente, por la sensibilidad. Sin embargo, es una parte de la razón, y Kant también se ve obligado a asumirla (por ejemplo, al asumir la "unidad incondicionada de las condiciones subjetivas de las representaciones en general", a la que llama apercepción trascendental y que no es más que una noción de sujeto, aunque bastante más des-sustancializada y cuidadosa que el cogito cartesiano). Me disculpo por citar largamente a Kant de nuevo, pero el pasaje que citaré explica su idea de lo incondicionado, tema que resulta fundamental para un texto clave que no podremos tratar aquí pero que es obligatorio para un próximo paso de este trabajo 22 .

En segundo lugar, lo que la razón busca en esta síntesis de las condiciones es propiamente sólo lo incondicionado o, por decirlo así, la integridad en la serie de las premisas que, juntas, no presuponen ninguna otra. Este incondicionado está contenido siempre en la absoluta totalidad de la serie, cuando ésta es representada en la

\footnotetext{
21 Ibidem, p. 185.

$22 \mathrm{Me}$ refiero a uno de los últimos textos de Derrida, en que retoma ampliamente la discusión sobre la aporía y su relación con la razón y con lo condicionado e incondicionado, así como con el idealismo trascendental de Kant, al cual está lejos de descartar o rechazar y antes bien transforma en uno de los temas más cercanos y necesarios para la deconstrucción. El texto es Canallas: Dos ensayos sobre la razón, Madrid, Trotta, 2005.
} 
imaginación. Pero esta síntesis absolutamente completa es, a su vez, sólo una idea; pues no podemos saber de antemano si semejante cosa es posible en los fenómenos. Cuando nos lo representamos todo por medio de meros conceptos del entendimiento, sin condiciones de la intuición sensible, podemos decir directamente que, para un condicionado dado, está también dada toda la serie de las condiciones subordinadas unas a otras; pues ese condicionado es dado sólo por esa serie (...) Ahora bien, ¿es posible esa integridad sensible? Esto es todavía un problema. Pero la idea de esa integridad se halla sin embargo en la razón, sin que se tenga en cuenta la posibilidad o imposibilidad de enlazar con ella adecuadamente conceptos empíricos. Así pues, como en la totalidad absoluta de la síntesis regresiva de lo múltiple en el fenómeno está necesariamente contenido lo incondicionado, pudiendo quedar indeciso sí y cómo esa totalidad ha de ser producida, resulta que la razón aquí toma la vía que consiste en partir de la idea de la totalidad, aun cuando propiamente su propósito último es lo incondicionado, ya lo incondicionado de toda la serie, o sólo de una parte de la misma ${ }^{23}$.

La segunda sección de la Dialéctica presenta la llamada "Antitética de la razón pura", en el marco de la cual Kant presenta cuatro pares de tesis/antítesis, en los que se afirman proposiciones que implican un uso trascendente de la idea trascendental de mundo (o unidad incondicionada de las condiciones objetivas en el fenómeno), es decir, son cuatro formas de la antinomia de la razón pura, "y cada uno de ellas no sólo no encierra en sí contradicción, sino que basta encuentra en la naturaleza de la razón condiciones que abonan su necesidad; sólo que desgraciadamente el teorema opuesto tiene por su parte fundamentos de afirmación igualmente valederos y necesarios" 24 .

Sólo mencionaremos estas oposiciones de las ideas trascendentales, constituyentes de la antinomia de la razón pura, basada en el uso trascendente de la idea de mundo, y que consideramos traduce casi por completo al concepto de aporía al que hemos venido haciendo referencia, ya que son inevitables, derivadas de la razón que naturalmente busca remontarse a lo incondicionado, e insolubles. Ninguna de estas tesis o

${ }^{23}$ CRP, tomo II, p. 190.

${ }^{24}$ Ibidem, p. 191, subrayado de Kant. 
antítesis puede ser demostrada en la experiencia, y en cambio ambas pueden y deben ser consideradas como plausibles si hacemos de ellas una consideración teórica. Es decir, son imposibles pero necesarias, e indican la experiencia de la no-experiencia o del no-camino, y con ello la condición aporética de la idea trascendental de mundo es su uso trascendente.

\section{Primera oposición de las ideas transcendentales}

Tesis: El mundo tiene un comienzo en el tiempo y con respecto al espacio está encerrado también en límites. (Es decir -aclaramos nosotros, cada vez- finitud espacio-temporal).

Antítesis: El mundo no tiene comienzo ni límites en el espacio, sino que es infinito, tanto en el tiempo como en el espacio. (Infinitud).

Segunda oposición de las ideas transcendentales

Tesis: Toda substancia compuesta, en el mundo, se compone de partes simples; y no existe nada más que lo simple o lo compuesto de lo simple. (Es decir, atomismo)

Antítesis: Ninguna cosa compuesta, en el mundo, se compone de partes simples; y no existe nada simple en el mundo.

Tercera oposición de las ideas transcendentales

Tesis: La causalidad según leyes de la naturaleza no es la única de donde los fenómenos del mundo pueden ser todos deducidos. Es necesario admitir además, para la explicación de los mismos, una causalidad por libertad. (O sea, libertad).

Antítesis: No hay libertad alguna, sino que todo, en el mundo, ocurre solamente según leyes de la naturaleza. (Determinismo por las leyes de la naturaleza).

\section{Cuarta oposición de las ideas transcendentales}

Tesis: $\mathrm{Al}$ mundo pertenece algo que, como su parte o como su causa, es un ser absolutamente necesario. (Necesidad). 
(La prueba de la tesis de la cuarta oposición es sorprendentemente análoga a la discusión sobre la estructuralidad de la estructura y su centro -arkbé, telos- que está fuera de la estructura ${ }^{25}$ ).

Antitesis: No existe en parte alguna un ser absolutamente necesario, ni en el mundo ni fuera del mundo, como su causa. (Contingencia).

4. Ahora bien, en la Crítica de la Razón Práctica, Kant hará una apuesta a partir de esta antinomia, de la que conocemos la necesidad con que se nos presenta y su correlativa imposibilidad de resolución, dada la imposibilidad -en la perspectiva de Kant- de cotejar las tesis o las antítesis recién ofrecidas en el marco de la experiencia, o bien determinar sin contradicción y de manera exclusiva y excluyente su necesidad por vía meramente teórica. Kant hace una apuesta ante el problema irresoluble de la aporía, toma una decisión fuerte por el polo de necesidad, que implica a la vez una fuerza performativa y una voluntad arquitectónica. Concretamente, decide privilegiar la libertad por sobre el determinismo en la tercera oposición de las ideas trascendentales. La idea de libertad es quizás el concepto central, el núcleo de mayor relevancia en la filosofía práctica kantiana, y de la mano del mismo el filósofo prusiano lidia con el problema aporético, construyendo una vía de escape. En honor a una saludable brevedad, iremos al grano, limitándonos a lo estrictamente necesario.

Si bien la libertad es una idea trascendental sin posibilidad de legítima aplicación en el mundo de los fenómenos (y esto según la razón pura o especulativa), el uso práctico de la razón nos obliga a considerarla de otra forma. "En este aspecto práctico puede y debe suponerse su posibilidad, aunque no conocerla ni inteligirla teóricamente. Para el último requisito es suficiente, en el aspecto práctico, que no contenga ninguna imposibilidad intrínseca (contradicción)", nos dice en el prólogo a la Crítica de la Razón Práctica. Es decir, por un lado, se diferencia entre la situación y los alcances de la libertad como idea trascendental, y su

${ }^{25}$ Cfr. Derrida, "La estructura, el signo y el juego en el discurso de las ciencias humanas", en La escritura y la diferencia. 
situación y alcances como concepto práctico, y sólo para uso práctico. En este segundo caso, el práctico, la libertad funciona como motivo determinante de la voluntad, y no como idea trascendental. Por otra parte, y como justificación para este cambio en el alcance y las posibilidades del concepto en cuestión, se invoca una razón arquitectónica, o bien, la condición arquitectónica que debe tener la razón misma, manifestada por el acercamiento a la idea de totalidad o visión de conjunto que implica esta síntesis de lo que antes se ofrecía sólo a un trabajo analítico. Se cierra así un círculo, se alcanza una unidad, que para Kant ya está allí, una unidad propia de la razón.

Ahora bien, la regla práctica es en todo momento producto de la razón, pero en el hombre la razón no es el único motivo determinante de la voluntad, ya que ésta se ve determinada por el apetito. Por lo tanto, esta regla debe ser un imperativo, es decir, "una regla que se designa por un deber-ser que expresa la obligación objetiva de la acción, y significa que si la razón determinara totalmente la voluntad, la acción tendría que suceder ineluctablemente según esa regla" 26 . Los imperativos categóricos son entonces leyes objetivas, que no tienen en cuenta el efecto ni la posibilidad de su realización, sino simplemente la determinación objetiva de la voluntad $^{27}$. Son incondicionales, universales, a priori, y se centran en la forma y no en la materia de la regla.

Es necesario recalcar la particular relación en que esta decisión o apuesta kantiana, generada en el seno mismo de la constatación del influjo inevitable de la aporía, sitúa a las actitudes de negatividad, positividad y la performatividad del como si (als ob) o del apuntar bacia.

En efecto, la ley moral demuestra su realidad añadiendo -de modo satisfactorio también para la crítica de la razón especulativa- a una causalidad pensada sólo negativamente, cuya posibilidad era incomprensible

${ }^{26}$ Kant, I., Critica de la razón práctica, Buenos Aires, Losada, 1968, p. 17.

27 El famoso "Obra de tal modo que la máxima de tu voluntad pueda valer siempre al mismo tiempo como principio de una legislación universal" (Ibidem, p. 28). 
para aquella aunque estaba obligada a suponerla, una determinación positiva, a saber, el concepto de una razón directamente determinante de la voluntad (mediante la condición de una forma legal universal de sus máximas), y de esta suerte puede dar por vez primera a la razón-que con sus ideas, si quería proceder especulativamente, caía siempre en desvarío- una realidad objetiva, aunque sólo práctica, y transforma su uso trascendente en inmanente ${ }^{28}$.

En este y muchos otros párrafos Kant hace explicita su apuesta de poner el fundamento (motivo determinante) de la ley moral más allá de las condiciones del mundo sensible, es decir, en lo incondicional -necesidad, universalidad- de la libertad. Semejante afirmación se sostiene, aunque no en palabras kantianas, en la performatividad esperada por el acto procedimental que pone en funcionamiento a la libertad como supuesto que permite la ley moral.

Ser objeto del conocimiento práctico como tal significa pues solamente la referencia de la voluntad a la acción mediante la cual él o su contrario se convierte en real, y el juicio de si algo es o no es objeto de la razón práctica pura es solamente la distinción de la posibilidad o imposibilidad de querer aquella acción mediante la cual cierto objeto llegaria a ser real si tuviéramos capacidad para lograrlo (de lo cual tiene que juzgar la experiencia) ${ }^{29}$.

Ahora bien, de esta performatividad producida por la elección de la libertad sobre el determinismo de las leyes naturales (en la tercera versión de la antinomia de la razón pura, o aporía) - con lo que se reconoce y se bace real en el hombre una dignidad superior a la de mera naturaleza condicionada, y por tanto se lo reconoce incondicionado- Kant deriva una noción fuerte de deber. Por otra parte, de la reivindicación positiva de la libertad en el momento aporético (polo de la necesidad por sobre el de imposibilidad, si bien éste también es reconocido en toda su dimensión) no sólo resulta la idea de deber, sino que, tras sutiles y extensas justificaciones,

${ }^{28}$ Ibidem, p. 45, subrayado nuestro.

${ }^{29}$ Ibidem, p. 55, subrayado nuestro. 
se termina por otorgar realidad a las otras ideas trascendentales ${ }^{30}$-aunque siempre esta particular realidad práctica y sólo para el uso práctico-, es decir, a la idea de mundo y a la idea de Dios (la idea de libertad corresponde a una realidad práctica del alma).

Así que la antinomia de la razón pura, que se hace patente en su dialéctica, es en realidad, el extravío más benéfico en que haya caido la razón humana, pues acaba induciéndonos a buscar la clave para salir de ese laberinto, y si se la haya, todavía nos descubre lo que no buscábamos y sin embargo necesitábamos, a saber, una visión de un orden de cosas superior, invariable, en que estamos ya, y en adelante podemos ser instruidos mediante determinados preceptos a proseguir nuestra existencia en este orden, conforme a la suprema destinación de la razón ${ }^{31}$.

5. Hoy por hoy, sin embargo, tenemos nuestras propias constricciones, nuestras propias necesidades y nuestras imposibilidades. Tenemos que respetar las condiciones que propone o impone nuestra época y en ese sentido no podemos abrazar la solución kantiana de la aporía en su integridad. Siempre debemos estar sumamente atentos al modo en que tratemos con un filósofo como Kant, un filósofo que se encuentra -en palabras de Deleuze- en la bisagra del movimiento y el cambio de tantos conceptos $^{32}$. Un filósofo que introduce tantos cambios y pone en cuestión tantos lugares comunes del dogmatismo, pero que a la vez sigue estando preso, en varios sentidos, de una metafísica logocéntrica y oposicional como la que hemos caracterizado. Kant es además un filósofo que tiene la enorme particularidad de haber advertido y haber pensado precisamente esa condición de innovador, de estar tratando con temas y puntos de vista novedosos y capaces de influir en cambios radicales. Kant es un filósofo

30 Ya que en última instancia la razón pura o especulativa siempre está subordinada a la razón práctica, que le otorga la totalidad de las condiciones de su sentido. (Cf. Ibidem, pp. 112 y 113).

31 Ibidem, p. 99.

${ }^{32}$ Deleuze, G., Cuatro lecciones sobre Kant, en http://www.philosophia.cl. 
que piensa las antinomias de la razón pura, y con ello, su filosofía práctica surge directamente de una decisión tomada en el marco de las constricciones impuestas por esa condición antinómica de la razón. Es preciso rescatar ciertos espectros, ciertos fantasmas, de Kant, reconociendo a su vez que el Kant del deber y de la moralidad, así como el Kant de la analítica de la razón pura, el Kant sistemático, el Kant arquitectónico, es un Kant que no puede sostenerse hoy por hoy, en toda su dimensión, dentro del panorama filosófico contemporáneo. Hay que releerlo, discriminar sus pasos, sus procedimientos, analizarlo precisamente, ya sin la presión teleológica de volver a componerlo o unificarlo. Kant deberá quedar descompuesto, desunido, desmembrado en diversos espectros, que, a su pesar, exigen cuestiones distintas, tienen demandas heterogéneas.

Queremos establecer, así, algunas diferencias con su propuesta. 1) Kant comienza a pensar en la libertad, y la consiguiente ley moral -y así hasta la inmortalidad del alma o la existencia de un fundamento último como Dios-, a la manera de una posibilidad y una necesidad inmediatamente posterior, deducible de esa posibilidad (es decir, en la forma de un "puede $y$ debe ser pensada la libertad como...", etc.), que a poco de andar deriva en la afirmación fuerte de esa necesidad deducida, en el marco de la cual la mera posibilidad pierde ya su razón de ser, siendo su mención omitida, en adelante, por completo. Para nosotros, en cambio, debería ser al revés, es decir, sólo podemos afirmar la posibilidad de este transcurso, de este uso, de esta apuesta, pero no podemos proponer bajo ningún aspecto su necesidad, menos aún como si se tratase de un deber. Por tanto, todo rastro de deber que podamos encontrar en la filosofía práctica kantiana pasará a ser una posibilidad, un puede, casi como en la ética del "cuidado de sí", en que la prescripción es dejada de lado en beneficio de un marco abierto y heterogéneo de posibilidades. Abandonaremos la idea de deber sean cuales sean las consecuencias y sea o no posible hablar ya, en esas condiciones, de una filosofía kantiana, que se ve ciertamente horadada en sus fundamentos. 2) De ahí que no podamos suscribir en ningún caso la deducción trascendental de la inmortalidad del alma o la existencia de Dios, inscritas arquitectónica y teleológicamente en la afirmación positiva y performativa de la libertad como salida práctica 
del laberinto aporético. En el marco de nuestras constricciones contemporáneas, o al menos aquellas de las que nosotros nos hacemos cargo, estas ideas del alma y de Dios carecen de sentido. 3) Sí suscribimos, en cambio, la actitud kantiana, la decisión, el procedimiento del como si (als ob), del apuntar bacia; suscribimos también cierta idea de performatividad, aunque sólo podamos considerar metafórica la idea de que esta performatividad haga reales ciertas ideas ${ }^{33}$. 4) En este sentido es que proponemos la posibilidad (y ya no la necesidad, aunque estaríamos bastante cerca de eso) de producir una interrupción, un corte, una discriminación dentro de la filosofía kantiana: es preciso interrumpir el desarrollo kantiano que se inicia desde la base que supone la determinación de la necesidad de la libertad -esto es, la necesidad de "resolver" de algún modo la antinomia de la razón pura o aporía, o al menos apuntar bacia la apertura forzosa de un camino en este no-camino, o de actuar como si ese camino existiera, etc.-, y que se eleva hacia la determinación de un imperativo categórico, o la idea de ley moral, de deber, de inmortalidad del alma y de existencia de Dios. En otras palabras: acordamos con el análisis de la Dialéctica trascendental, en que se establece con lucidez contemporánea la permanencia irrenunciable de una aporía, y acordamos también con la performatividad de un como si que, a pesar de conocer en toda su dimensión la imposibilidad del transcurso a través de la antinomia -y precisamente a causa de esa imposibilidad-afirma sin embargo, casi positivamente, la también inclaudicable necesidad de la apuesta. No suscribimos, sin embargo, nada o casi nada de lo que Kant establece luego a partir de este acierto de su decisión o apuesta. Es decir, nos quedamos con esa actitud que está funcionando y motivando el transcurso y el movimiento entre las Críticas, pero no con el procedimiento particular que se erige de ahí en adelante, y mucho menos con las conclusiones que se construyen en base a ese procedimiento.

3. Aun cuando Claude Lefort ha mostrado convincentemente en La invención democrática la posibilidad del acto performativo para la materialización de ciertas demandas; por ejemplo, la inscripción de ciertas demandas en la forma de una ley, que lleva al establecimiento efectivo de ciertos derechos humanos antes inexistentes. 
En lo que dijimos en el primer punto sobre las diferencias que establecimos respecto de Kant, se apoya lo que decimos en la cuarta diferencia, es decir, que la aporía no tiene una solución, pero que aun así debemos-podemos buscarla. No prescribimos tampoco una forma particular de transcurso a través de la antinomia, sino que revisamos una posibilidad para intentarlo. De esta forma creemos acercarnos a la fijación de un pequeño reducto conceptual que nos permita comenzar una indagación futura a partir de cierto asidero, de cierta apoyatura -la posibilidad de performar una desmarcación (cuando no una eliminación) del problema aporético-, reducto que respeta el conocimiento actual sobre la imposibilidad de fijar un sentido, dada nuestra constricción contemporánea de no poder recurrir a fundamentos trascendentes para utilizarlos como criterios externos (externos a la actividad política, si se quiere), pero a la vez, la necesidad fáctica de cierres, suturas, nombres, identificaciones, que serán siempre parciales ${ }^{34}$.

En este marco es que se hace preciso investigar si este perpetuo choque productor de identidades inscritas sobre una tensión inerradicable, no es, en cierto modo, y precisamente desde su condición de perpetuidad o de "fundamento" de lo pos-fundacional, una condición trascendental de la razón (en la forma de un conocimiento sintético a priori, tal como Kant muestra en la Dialéctica trascendental, y que por tanto podría -y quizás, incluso, debería, y éste es el único lugar donde nos permitimos el uso de la palabra deber- ser considerada activa y constantemente a la hora de pensar un procedimiento que, como mínimo común denominador de cualquier manifestación-aplicación de la razón, apunte o quiera apuntar todavía al problema de la justicia). La apertura a la alteridad (la ética levinasiana), el acontecimiento, la composibilidad, o la diferencia entre el derecho y la justicia, y la justicia como deconstrucción, asumen esta tarea de la justicia, una tarea incondicional (en el sentido derrideano-kantiano) y necesaria.

Recibido: 11/2010; aceptado: 12/2010.

${ }^{34}$ Cfr. Rinesi, Eduardo, Politica y tragedia. Hamlet entre Hobbes y Maquiavelo, Buenos Aires, Colihue, 2003. 